\title{
Fugindo para a Força: Cultura Corporativista e "Cor" na Polícia M ilitar do Estado do Rio de Janeiro*
}

Livio Sansone

Resumo

0 objetivo deste artigo é apresentar os resultados preliminares da pesquisa "O N egro na PM", realizada em 2000-2001, cujos principais objetivos foram lançar luz sobre a carreira dos afro-brasileiros na PM , como é coloquial mente chamada essa Força Policial, e também sobre os discursos em torno da "raça" e da identidade negra. Assim, foram analisadas as condições detrabal ho e da realidade cotidiana das tar efas policiais da PM , que se especial iza no policiamento ostensivo uniformizado. Foram realizadas cinqüenta entrevistas em profundidadecom soldadose oficiais de quatro Batalhões e do Q uartel-G eneral da Polícia M ilitar. E mbora a pesquisa não tenha a pretensão de ser estatisticamente significativa, foi feito um esforço especial para conseguir um bom corte transversal da corporação. Para tanto, foi escolhido um Batal hão em uma região predominantemente pobre e, outro, em uma região quase toda de classe média. Q uase metade dos informantes eram soldados, compondo-se os demais de oficiais de diversas patentes. Embora o foco tenha incidido sobre os policiais negros, também se entrevistou um pequeno grupo de controle composto por PM s brancos.

Palavras-chave: raça, cor, afro-brasileiros, identidadenegra, Polícia M ilitar do Estado do Rio de Janeiro.

\footnotetext{
* Tradução de Vera Ribeiro do original "Running away into the Force Corporate culture and 'colour' in the M ilitary Police of the State of Rio de Janeiro".
}

Estudos Afro-Asiáticos, Ano 24, no3, 2002, pp. 513-532 


\section{Abstract}

Going to the Force: Corporately Culture and "C olor" inside the Rio de Janeiro State M ilitary Police

This article's object isto show the preliminary results of a research called "The N egroes on the M ilitary Police", which main purpose is to present the careers of African-Brazilians on the M P - how it is often called this Police Force - and to present speeches about race and the $\mathrm{N}$ egro identity. Therefore, work conditionsand the day-after-day reality of the M P tasks were analyzed, being this latter specialized in ostensive uniformed policing. Fifty in-depth interviews were made with soldiers and officers from four battalions and from the M ilitary Police $\mathrm{H}$ eadquarter. Although this research was not intended to have statistic significance, a especial effort was made to do a deep study inside the corporation. To do that, one battalion was chosen in a predominantly poor area, and another one in a middle-class area. Almost half of the interviewed were soldiers, the others being officers of several ranks. In spite the focus of the research was N egro policemen, a small group formed by white $\mathrm{M}$ ilitary policemen has al so been interviewed.

Keywords: race, color, Afro-Brazilians, $\mathrm{N}$ egro identity, R io de Janeiro State M ilitary Police.

\section{Résumé}

Se Réfugiant dans le Force: C ulture Corporative et "C ouleur" à la Police M ilitaire de Rio de J aneiro

Le but de cet article est de présenter les premiers résultats d'une enquête sur « Le N oir à la Police M ilitaire (PM) » dont les principaux objectifs étai ent d'éclai rer la carrière des afro-brésiliens de la PM , nom donné à cette «Force de Police», mais aussi sur les discours autour de la notion de «race » et l'identiténoire. Ainsi, on a analyséles conditions de travail et la realité quotidienne des tâches assignées aux policiers de la $P M$, qui se sont especial isés dans la surveillance policière intensive faite par des PM en uniforme. O $\mathrm{n}$ a fait cinquante interviews approfondies avec des soldats et des oficiers de quatre casernes et du Q uartier $\mathrm{G}$ énéral de la Police M ilitaire. M ême si cette recherche ne prétend pas être statisquement représentative, il y a eu un effort particulier pour obtenir une coupure transversal e de cette corporation. Pour ce fai re, on a choisi une caserne située dans une région à population dominante particulièrement pauvre et une autre située dans une région où la classe 
moyenne était importante. Presque la moitié des informateurs étaient des soldats et, les autres, des oficiers de différents grades. M êmesi I'on a centré cette recherche sur les policiers noirs, un petit groupe contrôle, constitué de PM blancs, a été égal ement interviewé.

M ots-clés: race, couleur, afro-brésiliens, identiténoire, PM del'État de Rio de Janeiro. 
No estudo das relações raciais, é preciso encontrar um ponto de equilíbrio entre a curiosidade pela natureza e pela lógica das identidades etno-raciais e um certo grau de ceticismo quanto a qualquer "valor" intrinsecamente libertário e emancipador da identidade étnica.

Esse tipo de ceticismo saudável e engajado vai de encontro à tendência de muitos antropólogos de se concentrarem em pessoas e grupos com os quais eles se sentem capazes de estabelecer uma certa empatia. A busca de empatia talvez tenha sido mais intensa do que em outras áreas na prática da antropologia da identidade étnicae das relações étnicas eraciais. Em muitos casos, os antropólogos não só tomam partido, como eles mesmos e seus produtos tornam-seimportantes para conferir autoridadeatal ou qual traço da manifestação da identidade (H andler, 1988).

H istoricamente, desdeseus primórdios, nasúltimas décadas do século XIX a antropologia das produções culturais afro-brasileiras tem confirmado essa tendência. 0 Brasil viu antropólogos atuarem como participantes e até porta-vozes desta ou daquela tendência, por exemplo, do sistema religioso sincrético do candomblé. Antropólogos de al to nível não só exibiram uma predile ção pelas culturas negras do Brasil, como também se tornaram paladinos da pureza e daquilo que perceberam como "autenticidade africana", em contraste com a mistura cultural indiscriminada (Silva, 2000; Sansone, no prelo). Esse tratamento preferencial de um número sel eto de traços culturais exerceu grandeinfluência sobre aspectos da vida das populações afro-brasileiras consideradas interessantes ou apropriadas para a pesquisa, e das que não eram vistas desse modo. A mobilidade social recebeu pouquíssima atenção, porque se presumia que a cultura e a identidade negras estariam intrinsecamente relacionadas com a situação da classe baixa. Ao subir na escala social, o negro brasi leiro se tornaria branco - os cientistas sociais simplesmentetomaram por certa a opinião popular dequeosnegrosquese "saíam bem" em termosfinanceiros, "viravam brancos" em al gum momento de sua vida. $N$ a verdade, essa 
incompatibilidade entre a mobilidade social e a negritude contraria a história de participação dosnegrosbrasil ei rosna classemédia, em todas as etapas da luta dos negros- desdea luta pela al forria até a que foi travada pela abolição e, mais tarde, pela emancipação social. 0 utros aspectos que têm recebido pouca ou nenhuma atenção, até hoje, são a construção de identidades múltiplas ou fragmentadas - a situação híbrida inerente a boa parte da vida sócio-cultural dos afro-brasileiros - ea inter-relação da "raça" com a classe na vida cotidiana.

U ma combinação especial de ceticismo e curiosidade faz-se extremamente necessária ao optarmos por nos concentrar num objeto de pesquisa que, em vez do exótico, apresenta uma combinação do conhecido e do "ofensivo" - daquilo que um homem de orientação esquerdista no final da casa dos quarenta anos, como eu, tendea perceber como violento, machista e simplesmente errado.

Tal é o caso da Polícia M ilitar do Estado do Rio de Janeiro, com seu efetivo de 30 mil policiais. Trata-se não apenas de uma corporação grande e relativamente "negra", mas também de uma instituição muito masculina ${ }^{1}$ emuito violenta- em especial contra a população não-branca easclasses baixas, em termosmaisgerais.

O s objetivos desta pesquisa foram dois. Q ueríamos lançar luz sobre a carreira dos afro-brasileiros na PM , como é coloquialmente chamada essa Força Policial, e também sobre os discursos em torno da "raça" eda identidade negra. Para tanto, também precisávamos dar uma idéia das condições de trabalho e da realidade cotidiana dastarefas policiais da PM , que se especializa no policiamento ostensivo uniformizado, deixando o trabalho de detetive e as atividades policiais ligadas ao sistema judicial a cargo da Polícia Civil, muito menos organizada e hierarquizada (e bem mais corrupta, ainda que, possivelmente, menos violenta). Creio que, na construção de nosso objeto de pesquisa, o empenho em procurar lançar luz também sobre pessoas cujas motivações e impulsos pessoais temos dificuldade de entender, ou que, a rigor, nos desagradam sob muitos aspectos, significa um passo à frente na busca de uma proximidade nova e franca na prática da etnografia (Fabian, 1983), bem como, em linhas mais gerais, na discussão de al gumas das premissas do tipo de autoridade etnográfica que se baseia na empatia afetiva entre o etnógrafo e o informante.

C oligimos cinqüenta entrevistas detal hadas com soldadose oficiais de quatro Batalhões e do Q uartel-G eneral da Polícia M ilitar. Embora a pesqui sa não ten ha a pretensão de ser estatisticamente significativa, fez-se um esforço especial para conseguir um bom 
cortetransversal da corporação. Por isso, escolhemosum Batalhão numa região predominantemente pobre e outro numa região quase toda de classe média. A proximadamente metade dos informantes foram soldados, compondo-se os demais de oficiais de diversas patentes. Embora o foco tenha incidido sobre os policiais negros, também se entrevistou um pequeno grupo de controle composto por PM sbrancos - osquais, muitas vezes, eram colegas diretos dos policiais negros entrevistados. E deparamos com uma situação bastante complexa.

A hierarquia militar da PM apóia-se numa combinação de normas escritas e rígidas e de cultura corporativista. Esta última tem sido tema de pesquisa de historiadores, mas raramente de etnógrafos, o que, por certo, tem a ver com a relativa dificuldade de obter acesso a essa instituição militar. $\mathrm{N}$ aúltima década, entretanto, essa ausência da etnografia, uma vez que o processo de democratização chegou à sua conclu são neste país antes bastante autoritário, relaciona-se, sobretudo, com uma das principais deficiências das antropologias brasi leira e no Brasil. Trata-se da tendência a uma concentração naqueles que são percebidos como vítimas, e não nos que vitimam; nos fracos, e não nos poderosos; naqueles com quem podemos estabelecer um sentimento de empatia, e não naquel es por quem não sentimossimpatia al guma (C orrêa, 1995).

Estabelecer um sentimento de empatia com a PM foi difícil. Ao fazermos o trabal ho de campo na corporação e ao lermos as entrevistas, meus assistentes de pesquisa eeu tivemosdenosabster de levar nosso objeto de pesquisa a parecer demoníaco, porque isso não ajudaria a compreender o mecanismo de dominação que queríamos investigar. C reio que o trabal ho de campo realizado na PM correspondeu à minha chegada à maioridade como antropólogo, tendo uma função terapêutica que pode contribuir para livrar minha manei ra de exercer a antropologia da ten dência a el aborar projetos de pesquisa demasiadamente reduzidos, o que significa deixar sem consideração muito daquilo que seria importante, como as culturas corporativistas produzidas na polícia e no Exército.

A carreira dos negros na PM é esclarecedora no que tange à interligação da cor e da classee à complexidade da criação da identidade. Por um lado, historicamente, a PM tem sido um veículo importante de mobilidade social para os afro-brasileiros, do mesmo modo que vários outrostipos de "empregos deuniforme". N esse processo, a "raça" e a classeficam estreitamenteinterligadas. Por outro lado, os afro-brasileiros desenvolveram um conjunto muito complexo de atitudes dentro dessa corporação, o que pode ser afli- 
tivo para quem gosta de pensar na negritude como uma "etnicidade inocente" de fato (H all, 1999) - sempre do lado certo, nunca errada. V ejamos por quê.

\section{A Força do U niforme}

N o Brasil, a cor escura da pele tem uma estreita associação com a classe baixa. Tradicional mente, os afro-brasilei ros têm uma representação exagerada entre os pobres e até entre os chamados "pobres indignos" - delinqüentes, prostitutas e vagabundos. 0 emprego uniformizado tem sido uma saída tradicional da pobreza para os afro-brasileiros. N o caso dos escravos, a M arinhafoi um lugar para el es escaparem de sua situação e se tornarem marinheiros, sob a proteção de capitães que freqüentemente os escondiam da polícia ou dos mercenários dos senhores de escravos (Pereira, 2000). A própria polícia - apesar de historicamentetolerante para com os brasil ei rospoderosos ebrutais, em detrimento dosbrasileiros pobres, entre os quais os negros têm representação majoritária - , assim como outras milícias, semprefoi também uma instituição que ofereceu refúgio aos alforriad os durantea escravidão e aosbrasileirosnegros apósa abolição da escravatura, em 1888 (H olloway, 1997).

O funcionalismo público, a polícia e o Exército foram uma via importantíssima de mobilidade social para os brasileiros negros, especial mente a partir da ditadura populista de $G$ etulio Vargas, na década de 1930, a qual, depois de um período deimigração maciça de europeus, criou quotas no serviço público e nas empresas estatais para a população brasileira nata, predominantemente preta e parda. Entretanto, a importância desse tipo de empregos é um dos traços comuns na situação da população descendente de africanos nas diferentes regiões e países do Atlântico N egro. Em países e regiões conhecidos por seu mercado de trabalho etnicamente segmentado, como 0 C aribe de línguas inglesa e holandesa, bem como em países e regiões cujo sistema de relações raciais é centrado em um continuum de cor e em um entrelaçamento mais complexo da classee da "raça" ou etnicidade, a população negra saiu-se bem melhor no serviço ativo, no funcionalismo público e nas empresas estatais do que no setor privado. Essa dependência do Estado teve conseqüências para as estratégias políticas, uma vez que, para conseguir um emprego público, muitas vezes era preciso construir alianças e participar, em al guma medida, da relação cli- 
entelista. E também teve conseqüências para a situação trabal hista. A partir do processo geral de retraimento do Estado e redução dos gastos públicos que se verificou no Brasil e em outros países das Américas, os negros parecem fazer parte do setor da população que mais foi afetado por essas mudanças econômicas.

Essa combinação entre a estreita associação da pobreza com a tez escura e a dependência excessiva do emprego de uniformelevou a um paradoxo muito interessante. $\mathrm{H}$ oje, como no passado, os negros têm uma enorme representação na força policial e no "público policial", uma vez quea maciça maioria das pessoas detidase presas pela PM são "pobres indignos" - pequenos delinqüentes, prostitutas, "aviões" dos escalões inferiores das quadrilhas detraficantes, meninos de rua, sem-teto, bêbados, etc. Pelo menos no B rasil a mai oria dos confrontos entre "polícia e ladrão", portanto, compõe-se de fenômenos que, pelo menos na mídia, opõem homens pretos a outros homens pretos - a tel evisão ea imprensa oferecem diariamente uma profusão dessas imagens. ${ }^{2}$

Com 30 mil integrantes (aos quais podemos acrescentar mais de 17 mil aposentadoseo efetivo de 15 mil homens do C orpo deBombeiros, quefaz partedaPM ), essa grandecorporação éo segundo maior empregador do Estado do Rio de Janeiro, logo depois da Prefeitura do Rio de Janeiro. É também um grande empregador de não-brancos em todos os níveis.

$\mathrm{N}$ aturalmente, levando em conta a estreita associação entrea pel e escura e a baixa classe social, típica da sociedade brasileira, os policiais de cor têm maior representação nos escalões inferiores. Entretanto, segundo nossa estimativa, com seu total de 43\%, também entre os oficiais os não-brancos estão bastante bem representados. Embora não disponhamos de cifras comparativas, é nossa impressão, bem como a dos policiais que entrevistamos, que os brasileiros pretos e pardos têm uma representação muito maior e mais eqüitativa na PM do que em qualquer empresa privada, ou mesmo em qualquer empresa ou instituição pública do Estado do Rio de Janeiro.

$\mathrm{N}$ as entrevistas que real izei com coronéis do $\mathrm{Q}$ uartel- $\mathrm{G}$ eneral do Rio, em 1999, a situação da PM tendeu a ser comparada à de outros dois grandes empregadores - o Exército euma empresa privada. 0 Exército étido como tão universalista em seus critérios de recrutamento e carrei ra quanto a PM , até o posto de coronel. D aí para cima, contudo, atéos postos degeneral emarechal, asnomeações resultam de indicações políticas. Por essas razões, segundo nos foi dito, existe um único general negro num total de mais de 
cem, e os generais brancos tendem a "ter três sobrenomes" (provindos de famílias quatrocentonas, aquelas famílias tradicionais que datam dos tempos do Brasil colonial). O s coronéis entrevistados também compararam a PM a uma empresa privada, a V arig, a maior das companhias aéreas brasileiras, vista por eles como tendo pouquíssimos não-brancos, sobretudo entre os pilotos, e acusada de ser "racista", ao contrário da PM . A Polícia M ilitar, afirmaram eles de cabeça erguida, assegura a cada um de seus membros as mesmas oportunidades de mobilidade social dentro de sua rígida hierarquia e suas fileiras. Se o indivíduo for um bom soldado, conseguirá subir até o posto de sargento - no devido tempo e cumprindo todas as normas e regulamentos. Do mesmo modo, um subtenente, primeira patente da carreira de oficial, chega ao posto de tenente e, passados uns quinze anos, ao de capitão. Al guns podem até chegar a coronéis - dos quais existem 88. M as ninguém chega ao posto de general, porque as normas de padronização da força estadual da Polícia M ilitar, redigidas durante a ditadura do período de 1964-1985, restringem a nomeação de generais ao Exército. É o presidente do país que nomeia os generais. Para tristeza dos coronéis que entrevistei, portanto, o chefe da corporação é al guém que el es percebem como bastante híbrido em termos da hierarquia militar: um comandantegeral, queé um coronel nomeado pelo governador do estado. Para piorar as coisas, os dois últimos governadores do Estado do Rio de Janeiro nomearam um general de Exército (já reformado) como chefe da Secretaria de Segurança Pública do estado. A PM sente-se fazendo o trabal ho pesado, mas sem desfrutar do status, do dinheiro, da influência política e da popularidade do Exército.

SeaPM sesente "discriminada" pel o Exército e pelo governo federal, não se pode dizer que ela mesma seja uma instituição muito democrática. Em termos de origens sociais, é bastante segmentada. $\mathrm{N}$ a verdade, há duas portas de entrada bem diferentes na corporação, uma para os praças(soldados) e outra para os oficiais. As duas funcionam por concurso, ou seja, por uma concorrência pública bem divulgada e que atrai mais candidatos do que o número de vagas disponíveis. As condições de trabal ho, os salários, a aposentadoria e os benefícios variam muito. Assim, um coronel recebe até o equivalente 1.900 dólares líquidos mensais, após a dedução dos impostos, enquanto um soldado ganha apenas cerca de 250. Além disso, embora a corporação se orgulhe reiteradamente em propalar sua política e sua cultura universal istas, segundo as quais todos os policiais são igualmentetratados e to dos os cidadãos rece- 
bem o mesmo tratamento, há provas de queisto nem sempreacontece e de que, em especial, o modo como os cidadãos são tratados varia muito, conforme seu statussocial eseu "valor" - o quesignifica, muitas vezes, o dinheiro de que el es dispõem para subornar os policiais.

Atualmente, os negros também formam um grupo considerável entre os oficiais. Ele vem aumentando nas últimas décadas, mas tornou-se mais visível quando, no governo do líder populista de esquerda L eonel Brizola, pela primeira vez um negro tornou-se comandante da PM - o famoso coronel Carlos M agno N azareth Cerqueira, que chefiou a C orporação por dois mandatos consecutivos, num total deoito anos. D eacordo com nossos cálculos, mais de $50 \%$ dos al unos da Academia dePolícia, que prepara os futuros oficiais, são pretosepardos. D adososmecanismos automáticos da carreira na Corporação, dentro de um prazo de aproximadamente dez anos os brancos serão minoria entre os capitães e sua proporção entre os coronéis será muito inferior aos cerca de $70 \%$ atuais. A amplitude dessa presença negra pode ser explicada de duas maneiras. Primeiro, muitos se sentem atraídos pelo emprego seguro, com uma carreira automática e benefícios indiretos - apesar do enorme perigo do trabalho, num contexto violento como o do Rio de Janeiro. No Brasil, já existe uma tradição de que o trabalho na PM éalgo acessível ou, pelo menos, "possível" para negros de diferentes posições sociais. A PM também tem oferecido a muitos a possibilidade de fazer estudos paralelos e desenvolver qualificações diferentes - sobretudo na área do D ireito. I sso explica a crescente rotatividade na Corporação: hoje em dia, os novos recrutas, especialmente os mais instruídos, tendem a permanecer na força policial por períodos mais curtos do que no passado. Para um número cada vez maior de rapazes, a PM é um trampolim para outro emprego. O utra razão da relativa granderepresentação de brasil leiros pretosepardos em todos os escalões dessa força éo fato de quea população branca tem tido maiores alternativas de ascen são social, edeque, no Rio de Janeiro, mais do queem outros estados, a classe média-alta branca não identifica a carreira no comando da PM como algo adequado ou desejável.

\section{A Cultura Corporativa/Corporativista}

Estamos falando de uma Corporação altamente segmentada, na qual soldados e oficiais compartilham uma cultura corpora- 
tiva comum. Essa cultura tem um bom grau de resistência à mudança política. Assim, quando há uma grande guinada política para a esquerda ou para a direita no governo do Estado do R io de Janeiro, a PM , em vez de modificar sua estrutura e suas normas, adapta-seà mudança, garantindo a substituição temporária de oficiais de esquerda por oficiais de direita, ou vice-versa, nos postos-chave.

Apesar dessa cultura comum, os integrantes da PM vivenciam condições de trabal ho muito diferentes. Para começar, os soldadosficam mais expostos ao perigo e, por conseguinte, têm muito mais probabilidade de figurar entre os mais de cem policiais mortos em ação, a cada ano, nesta última década - emuitos outros são mortos nas ati vidades de guarda-costas ou guardas de segurança que vários del es exercem paralelamente, para aumentar seu magro salário. O suniformes, o equipamento, as armas, a al imentação e os dormitórios também são muito piores, assim como os ben efícios de aposentadoria e os seguros de saúde - os soldados têm que depender dehospitais da rede pública, enquanto os oficiais têm seguro de saúde privado. Além disso, seguindo o padrão dos empregados de mais alto escalão no serviço público brasileiro em geral, os oficiais podem aposentar-se muito mais cedo e contam com a possibilidade de combinar seu salário com a renda proveniente de nomeações políticas. C omo resultado relativamente lógico, as associações corporativas (os sindicatos não são permitidos, em vista desua condição de militares) também se dividem deacordo com as patentes. A Associação de Cabos e Soldados é a mais forte e mais "militante", seguida pela Associação de Sargentos e pela Associação de 0 ficiais. Todas têm clubes de lazer muito ativos e intensamente freqüentados. C onjuntos de samba eatéagremiações populares de poesia têm usado muito os dois primeiros tipos de clube, que ganharam fama como locais culturais animadose baratos, mas seguros. N ão éà toa que o hino da Polícia M ilitar do Estado do R io de Janeiro é um samba, composto por um PM queé autor de sambas populares.

Essa realidade "separada, mas igual" dentro da PM - com "classes" diferentes associadas às diversas patentes - está relacionada com uma cultura corporativa interessante e intrigante, para a qual contribuem todos os setores da força policial e que é reinterpretada de maneiras diferentes, conforme a posição hierárquica de quem fala. Para os soldados, a existência de uma C orporação grande eabrangente éum instrumento para a rei vindicação de um certo grau de igualdade de tratamento e de condições de trabalho. 
Para os oficiais, a "cultura da PM ", como el es a chamam, éum instrumento para exigir conformidade e obediência dos subordinados às regras e valores (deles próprios). Para os soldados, a democracia pode e deve combinar-se com a hierarquia militar, ao passo que, para os oficiais, hierarquia e democracia são inconciliáveis.

Essasidéias sobreaigual dademilitar, questionadase amiúde alternativas, fazem lembrar os discursos contestad os sobre o tema da "democracia racial" - sobreo credo, ou, para al guns, o mito, em torno do qual devegirar a sociedadebrasileira. A igualdaderacial é vista de uma perspectiva diferente, dependendo da posi ção hierárquica de quem fala: para o setor pobreepredominantemente preto da população, éo sonho deum mundo melhor emaisjusto; para as pessoas de posses, éum si stema sócio-racial sumamente hierarquizado, no qual o equilíbrio ea harmonia dependem da ordem e da submissão dos pobres. 0 u seja, tanto a classe baixa quanto as classes média e al ta contribuem, cada qual a seu modo, para a manutenção e a renovação do discurso sobre a democracia racial.

Passemos, agora, a uma rápida olhadela no uso da "raça" dentro da Força Policial. O s policiais negros geralmente se sentem protegi dos pela Corporação; a despeito detodos os riscos possíveis que correm, eles afirmam conhecer poucas outras situações em que os brasileiros negros possam sentir-se "gente" como na PM. D entro das limitações, mas igualmente da orientação da hierarquia militar, eles também se sentem "respeitados" como em nenhum outro lugar. O s mecanismos capazes de levar à ascensão na PM são claroseenunciados por todo o mundo, em al to ebom som, ao contrário do que acontece "lá fora", onde as coisas podem ser muito confusas - às vezes, o sujeito não sabe se é bem-vindo ou benquisto, por causa da cor da pele. $\mathrm{N}$ a polícia, ele progredirá devagar, mas de modo certeiro, se souber conduzir-se direito, cumprir as ordense rituaise "casar-se" com aPM - esposando integralmente sua cultura corporativista, a ponto de ela não ter quel he ser imposta nem ensinada, por fal ar através dele, já queo policial simplesmente a aprendeem sua experiência cotidiana. Q uasetodos os entrevistadosmanifestaram al gum grau defidel idade afetiva à $F$ orça. Para eles, esta é uma grande família, um sindicato, um grande grupo de pares, o templo da masculinidade, a partelimpa de uma sociedade podre, ou o lugar e a hora em que as coisas ficam claras, num mundo em que tudo se torna cada vez mais obscuro. Para muitos, ela é um pouco de tudo isso. A maioria não se incomoda com a autoridade dos superiores e até tolera seu comportamento abusivo, desde que este se expresse de acordo com a hierarquia e os 
rituais da universali dade, segundo os quais qualquer homem pode ser (tolerantemente) punido, masnunca humilhado. Eles contrastam a Força com o mundo externo, no qual o abuso predomina ea lei e os deveres não são iguais para todos. A questão ésaber até que ponto a própria Força não contribui para a distribuição desigual e injusta dos direitos e deveres e, sob o manto dos critérios universais - "somos a mesma força policial para todos" - , até que ponto ela não reforça, na verdade, interpretações particulares e privadas do cumprimento dalei. Será quea igualdade (racial) dentro daPM e a criação e a defesa militante de uma cultura corporativa hierarquizada e protetora não são um preço al to pela forma como a Força lida com "o mundo"? Como se relaciona a questão da diferença de cor com esse contexto hierárquico?

0 mundo externo é freqüentemente retratado como uma realidade invertida, na qual cada cidadão é potencial mente culpado de al guma coisa, e a Força tem a tarefa ingrata e implacável de fazer as coisas funcionarem, mantendo-as em ordem. N essas descrições, o componente maléfico do "mundo" é, com certeza, a mídia: são os meios de comunicação de massa, afirmam os policiais, que viram a realidade de cabeça para baixo, por serem inimigosintrínsecos de qualquer forma de policiamento. A mídia, dizem eles, defende os direitos civis dos bandidos, mas não os das vítimas, e menos ainda os dos policiais.

Segundo eles, as pessoas de fora não têm como entender inteiramente o cotidiano da PM. Por sua vez, só quem passou por "tudo isso" é capaz de compreender essa rotina, com suas regras e segredos. Só os que conhecem o cotidiano em primeira mão podem compreen der aPM esua ação. Professando essa "visão de dentro", os policiais que entrevistamos procuraram legitimar seusatos (e sua brutalidade) e enfatizar a existência de algo essencialmente diferente, uma espécie de melancolia do policial.

O s "bandidos" são descritos como o oposto diametral dos PM se, a rigor, indignos de continuar vivos- na verdade, deveriam ser executados (o que acontece com regularidade espantosa). O s policiais negros não parecem diferir de seus colegas não-negros ao denunciarem a mal dade do "mundo lá fora" eafirmarem a necessidade delivrar a sociedadedos "bandidos", liquidando-0s. Aliás, ao entrevistar rapazesnão-brancos da classe baixa do Rio de Janeiro, é muito comum ouvir que os moradores das favelas têm mais medo dos PM s que dos "bandidos" e que os policiais negros são ainda mais violentos do que os outros - que o jovem negro prefere lidar com um policial branco. A razão disso, segundo se afirma, éque os 
PM s negros querem se exibir para seus superiores e deixar claro que não estão participando de nenhuma conduta ilícita. N ossa pesquisa não pôde propriamente desmentir essa opinião: chegamos à conclu são de que a violência se dissemina por toda a Força e atravessa todas as linhas divisórias da cor.

D o mesmo modo, se a Polícia M ilitar se rege por padrões universais, o mesmo não sepodedizer desua maneira de funcionar "no mundo". D e fato, não foi difícil chegar à conclusão de que, apesar das semel hanças formais entre to dos os batal hões locais, de seu efetivo, da qualidade desse efetivo, de sua idade e seu nível de instrução, o grau de violência e/ou eficiência queeles exibem varia consideravelmente conforme o contexto da classe social dos locais em que se situam essas unidades. $\mathrm{N}$ a Z ona $\mathrm{N}$ orte da cidade do R io de Janeiro, predominantemente de classe baixa, o policiamento é maisrude eresulta na morte deum número muito maior depessoas do que na Z ona Sul, mais rica. $\mathrm{N}$ a primeira, as pessoas são mais pobres, porém o clima geral de ilegalidade oferece mais oportunidades para as formas de corrupção em pequena escala eas atividades escusas paralelas - um acréscimo fundamental aos magros salários dos PM s. N a Z ona Sul, ao contrário, o policiamento é muito menosviolento e, por conseguinte, menosperigoso para os própriosPM s, porém émais difícil conseguir propinas, porqueas pessoas tendem a ser mais assertivas e mais difíceis de intimidar - "temos que tomar cuidado, porquea gente pode parar um sujeito e descobrir que ele é juiz ou filho de um juiz!"

A PM incorpora tipos de pessoas muito diferentes. À partea separação bási ca entre oficiais e soldados, há no oficial ato uma diferença importante entre os "tolerantes" e os "repressores". O s primeiros beneficiam-se atualmente do governo estadual de centro-esquerda, enquanto os últimos tiraram proveito do governo anterior de centro-direita (realmente muito violento). O s "tolerantes", em geral oficiais mais moços e mais bem preparados, preferem trabal har naZ Zna Sul, en quanto os "repressores" preferem a Zona N orte, onde a presença da mídia, das organizações não-governamentais e dos grupos de direitoshumanos é muito menor. 0 chefe da corporação está ciente da existência dessas duas alas e protege a ala "perdedora" quando o governo passa da esquerda para a direita, ou vice-versa, o que acontece regularmente no Estado do Rio de Janeiro.

Grosso modo, os policiais mais velhos têm dificuldade de lidar com as novas exigências de direitos civisque a sociedade brasileira vem criando. Alguns chegam a sentir saudade do passado, 
quando, segundo eles, a polícia era respeitada. H oje em dia, o uniforme (e a arma) ainda dá ao PM mais poder e respeito do que status (pelo menos no Rio), porém não oferece muito mais queisso etraz um enorme perigo. A violência e seu companheiro, o perigo, são presenças imanentes nessa Corporação, conhecida como uma das mais violentas e mais perigosas, por causa de seus soldados. A possibilidade deseferir em serviço ea conduta policial violenta caminham de mãos dadas: a mai oria das mortes acontece porque os policiaistêm medo deserem mortose procuram "antecipar" o desfecho em seu favor. Ser sujeito e objeto da violência cria um vínculo a mais, especialmente entre os soldados. Q uando entrevistei dois sargentos, ambos com cerca de cinqüenta anos - um branco e um negro - , ambos na Corporação há mais de trinta anos, o branco me disse:

- Entre nós não existe cor, estamos todos na mesma guerra; eu posso ser aquele que vai dar a ele o último gole de água. Temos que confiar uns nos outros e nos ajudar.

N uma mesma frase, a igualdade racial é celebrada ante a ameaça da morte. "A hierarquia e o perigo", dizem muitos PM s, "fazem com quetodos tenhamos a mesma cor: azul" (a cor do uniforme).

\section{A "Cor" na PM}

N o entanto, essa C orporação não é indiferente à "cor". Esta se acha presente nos papéis e no jargão do policiamento - "na ronda". Em várias ocasiões, como ao fazer relatórios por escrito, o policial é solicitado a descrever a cor de uma vítima ou de um suspeito. Em tese, isso deveria ser feito de acordo com o código formal de classificação racial no Brasil - o do Instituto Brasileiro de G eografia e Estatística (IBGE), que divide a população brasileira em cinco grupos, sendo quatro grupos de cor (branco, pardo, preto e amarelo) e um grupo étnico (índio). $\mathrm{N}$ a realidade, ao redigirem seusrelatórios, muitos policiais acabam usando maistermos designativos da cor do que apenas os cinco oficiais. Ao fazêlo, decerto são influenciados pela tradicional predisposição léxica da sociedade brasileira em matéria de vocábulos destinados a definir o próprio fenótipo ou o de terceiros (H arris, 1970). Essa predisposi ção está ligada a um hábito cultural brasileiro que é complexo, rico e relativizante no ato de denominar a cor ou a "raça", e que leva uma mesma pessoa a ser definida como tendo cores diferentes em dife- 
rentes contextos. 0 s policiais também são influenciados pelo fato de estarem habituados a um outro sistema classificatório mais antigo - o dos formulários que todos têm de preencher ao ingressar na C orporação. Esses formulários, concebidos há mais de cinqüenta anos, usam uma outra classificação racial, que reflete a grande influência do antropólogo criminalista C esare Lombroso nos sistemas policial e judiciário do Brasil, bem como de outros países da América L atina, desde o fim do século XIX atéa Segunda G uerra M undial. O s formulários são preenchidos pelo entrevistador (em contraste com a indagação sobre a cor no recenseamento nacional, que se baseia na autoclassificação) e, além de conterem informações relativas às dimensões corporaiseao tamanho dospés e da cabeça, incluem dados sobre o tipo e cor do cabelo e sobre a cor dos olhos. A cor da pele oferece cinco possibilidades, que vão do muito escuro (preto) ao muito claro (branco), com três grupos intermediários demestiços (moreno, pardo claro e pardo escuro).

Além desses dois códigos raciais formais, que muitas vezes se superpõem equesão importantes, por exemplo, para determinar a cor de um suspeito ou de um cadáver em um relatório, identificamos dois discursos bem mais coloquiais referentes à cor ou à "raça". Em primeiro lugar, existe uma grande diferença entre o dentro e o fora. D entro da Força, afirmam todos os entrevistados, o racismo não existe, ou éapenas ocasional eanômalo - decorrente dealgumas "maçãspodres" no seio de corporação intrinsecamente anti-racista, por centrar-se numa hierarquia militar e em patamares de carreira que são indiferentes à cor. Aí podemos identificar duas variações. Para a maioria dos entrevistados, sobretudo os soldados, dentro da Força praticamente "não existecor": "N aPM , somos todos azuis". Para uma minoria crescente de policiais negros, em geral mais jovens e mais instruídos e quase todos no oficialato, embora também haja soldados, a negritude tornou-se realmente uma coisa a ser apreciada. Entre eles, a negritude- ter consciência e orgulho da própria cor - , em vez de ser catal isadora de uma identidade étnica, é representada como um motivo a mais para estudar e trabalhar com afinco: é um discurso polido e assertivo sobre a mobilidade social e o aprimoramento educacional geral, no qual os brasileiros negros têm agora de mostrar, finalmente, que são tão bons e tão inteligentesquanto os outros. Esses policiai s vêem aPM como uma corporação hierarquizada, mas aberta e até potencialmente multicultural, na qual a mobilidade depende do esforço de cadaum ea cor não éuma variável de peso. Elesse solidarizam com outros policiais negros e especialmente com suas realizações na 
PM ou sua conquista de diplomas acadêmicos ou profissionais. $M$ as a negritude deles não é subversiva. Ao contrário, adapta-seà hierarquia eà cultura corporativa da PM - que é vista como aberta exatamente por dar uma oportunidade a esses negros em busca de ascensão social.

Fora da polícia, "no mundo", o racismo é muito mais reconhecido do que dentro da C orporação. R ealmente existe racismo na sociedade, segundo dizem sobretudo os policiais jovens e mais instruídos. N em todos, no entanto, concordam em quea PM seja particularmente racista em seu trabalho. A maioria afirma que ela simplesmente refl ete o clima da sociedade em geral. Em sua forma de verbalizar o racismo, pode-setraçar uma clara distinção entreos instruídos (em geral, oficiais) e os menos instruídos (em geral, soldados). Essa diferença foi acentuada pelo local em que se realizaram as entrevistas: a mai oria dos oficiais foi entrevistada no quartel-general daPM , ondetanto a linguagem quanto o clima tendem a ser mais descontraídos; os soldados, ao contrário, foram entrevistados quando retornavam ou partiam para "a ronda" - sempresuarentos, com fome ou com pressa. $\mathrm{N}$ a ronda, tanto a linguagem quanto o clima são bem mais rudes. ${ }^{4}$

De modo geral, falar em racismo vem se tornando menos tabu. H á uma mudança na geração mais nova, em decorrência do padrão educacional superior hoje exigido para o ingresso na Polícia M ilitar e da realidade da democracia, em contraste com a formação recebida durante a ditadura (1964-1985), como acontece com a geração mais velha de PM s. Essa mudança na nova geração também reflete uma tendência mais geral: até dez anos atrás, a maioria dos levantamentos e pesquisas de opinião mostrava que quase todas as pessoas negavam a existência de racismo no Brasil, ao passo que, hojeem dia, começa-se a aceitar a constatação de que ele existe. I sso é confirmado pelas pesqui sas sobre atitudes raciais no Brasil (D atafolha, 1995). Se hojeé comum a denúncia geral do racismo, entretanto, a maioria das pessoas, assim como quase todos os nossos entrevistados na PM , tem dificuldade de citar exemplos concretos de discriminação racial. 0 racismo, como se costuma dizer, é sempreal go que concerne ou afeta outras pessoas, nunca o próprio sujeito.

H á múltiplas razões pelas quais, ao falarem da cor e da "raça", todos os nossos entrevistados tenderam a preservar "sua" Corporação. Primeiro, como acabamos de mencionar, nossos informantes, tal como a maioria dos brasileiros, ficam muito mais à vontadeao falar do racismo em geral que de casos concretos de dis- 
criminação racial em seu meio imediato (Sansone, 1996). Segundo, ébastante plausível que, comparada a outrascorporações einstituições, a PM tenha conseguido minimizar ou expurgar as formas declaradas de racismo de suas fileiras - sua hierarquia e sua cultura corporativista não combinariam facilmente com políticas ou atitudes influenciadas pela cor. T erceiro, essa visão da cor e da Força está rel acionada com um quadro geral do "mundo" externo, percebido como predominantemente mau, podre e injusto.

\section{Contradições na C ultura Corporativista}

A igualdade, nos moldes de critérios universais, sem dúvida éuma vantagem, etem garantido uma certa medida demobilidade social ascendente aos afro-brasileiros em várias carreiras no funcional ismo público, no Exército e nas Forças Policiais. N a Polícia M ilitar do Estado do Rio de Janeiro, isto tem ocorrido dentro de uma rigorosa hierarquia militar em que são definidos direitose deveres, mas na qual os abu sos são organizados ou largamentetolerados e os privilégios se transformam em direitos. N esse caso, a emancipação através da carreira militar tem um preço alto: uma personalidade autoritária, a celebração do machismo e a construção de uma severa distinção nós-eles, capaz de implicar a brandura para com os abusos de poder dentro da PM e a implacabilidade para com as pessoas de fora ("o mundo").

A PM não é um espaço limítrofe, nem uma caixa fechada, em que todas as regras sejam previamente arranjadas, mas uma metáfora da sociedade brasileira. Ela reflete e amplia certas tendências gerais, como a aceitação de que os direitos civis são para poucos e de quea lei épara osinimigos, enquanto, para os amigos, tudo é possível.

N ossa pesquisa mostrou que, embora não seja cega para a cor, a PM é uma daquelas carreiras profissionais e áreas em que a "raça" é subsumida em outros fatores- em que classe, status ou patente têm mais importância e maior poder explicativo. Por essa razão, podemosformular a conclusão provisória deque, atualmente, na Polícia M ilitar predominantemente preta e parda do R io de Janeiro ainda não há espaço para o desenvolvimento de qual quer espécie ostensiva de formação da identidade negra.

0 exemplo da Polícia M ilitar do Estado do Rio de Janeiro é mais uma prova de que, afinal, as "identidades negras modernas", pretendidas como etnicidades relativamente auto-reflexas que 
buscam inspiração em fonteslocaiseinternacionais, como a “África", a Afro-América e/ou a D iáspora N egra, tais como as comumente associadas com os Estados U nidos ou com a representação desse país nos fluxos culturais globais, nem sempre parecem ser viáveis. T aisidentidades étnicas só emergem dentro e, quem sabe, depois de se conquistar um certo grau deliberdade, direitos civise bem-estar social, e podem, em outras circunstâncias, ficar subordinadas a outras pressões mais poderosas. ${ }^{5}$

\section{$\mathrm{N}$ otas}

1. Tradicionalmente, a Polícia M ilitar do Estado do Rio de J aneiro recruta muito menos mulheres do que a corporação equival ente de outros dois estados da federação brasileira, como São Paulo e Bahia (B ritto, 2001). Segundo um oficial, a razão do não recrutamento demulheres éque, "no Rio, o trabal ho é perigoso demais, eas muIheres não intimidariam os bandidos tanto quanto os homens". Pode-se argumentar que as mulheres contribuiriam para tornar a PM menos intimidante e, portanto, mais bem aceita pela população do que acontece hoje em dia.

2. É por essa razão que, no B rasil, não tendemos a ficar chocados com imagens como as do vídeo de 81 segundos que mostrou Rodney King sendo brutalmente espancado por seis policiais brancos de L os Angeles. As gravações em vídeo feitas por amadores tornaram-se parte integrante das reportagens da mídia sobre a brutalidade policial e os assassinatos de facto no Brasil. Entretanto, diversamente das situações norte-americanas de brutalidade policial, os brasil eiros pretos, nessas imagens, têm presença maciça entre as vítimas e os culpados.

3. O termo é genericamente empregado para designar qualquer pessoa envolvida em crimes de rua.

4. Entrevistamos mais de vinte oficiais no Q uartel-G eneral da PM .

5. Pesqui sas recentes mostraram que, no sistema penitenciário brasileiro, as relações raciaisficam submetidasa outraspressões, mais violentas etalvez "primárias" - a necessidade/direito de sobreviver numa instituição que pode ser letal (Leitão, 2001).

\section{Referências Bibliográficas}

BRIT T O , D yane (2001). Racismo ea Construção do Suspeito na Policia M ilitar em Salvador, Bahia. T ese de M estrado em Sociologia. Salvador, U niversidadeF Federal da Bahia.

CORRÊA, M ariza (1995). "A Antropologiano Brasil (1960-1980)". In: S. M iceli (org.), H istória das Ciências Sociais no Brasil, vol. II. São Paulo, ID ESP, pp. 25-106.

DATAFO LH A (1995). Racismo Cordial. São Paulo, Editora D atafolha.

FABIAN, J ohannes (1983). T imeand the 0 ther. N ovaY ork, C olumbia U niversity Press. H ALL, Stuart (1999). "W hat is Black in Black Popular Culture". In: G. D ent (org.), Black Popular Culture. ... . 
HARRIS, M arvin (1970). "Referential Ambiguity in the Calculus of Brazilian Racial Identity". In: N. W hitten e J. Szwed (orgs.), A frican-American Anthropology. N ova York, The F ree Press, pp. 76-86.

H O LLO W AY, Thomas(1997). Polícia no Rio de anei ro: Repressão e Resi stência numa Cidade do Século XIX. Rio de Janeiro, Editora da Fundação G etulio Vargas.

LEITÃO , K leber (2001). D o N egro Escravo ao N egro Preso. As R elações Raciais numa Penitenciária. Tese de M estrado em Antropologia, Salvador, U niversidade Federal da Bahia.

PEREIRA, Álvaro (2000). "D o C ativeiro ao M ar: Escravosna M arinha da G uerra”. EstudosAfro-Asiáticos, nำ38, pp. 85-112.

SAN SO N E, Livio (1996). "N em Somente Preto ou N egro. O Sistema de Classificação da C or no Brasil que M uda". A fro-Ásia, no18, pp. 165-188.

_ (no prelo). Blackness without Ethnicity. The Local and the Global in Black Cultural Production and Race Relationsin Brazil. N ova York, Palgrave.

SILVA, Vagner Gonçalves da (2000). 0 Antropólogo e sua M agia. São Paulo, ED U SP. 